\title{
O NOVO REGIME FISCAL BRASILEIRO E A DEMOCRACIA: INTERPRETAÇÕES SOBRE UMA INCOMPATIBILIDADE
}

\author{
THE NEW BRAZILIAN FISCAL REGIME AND DEMOCRACY: \\ INTERPRETATIONS ABOUT AN INCOMPATIBILITY
}

\author{
EL NUEVO RÉGIMEN FISCAL BRASILEÑO Y LA DEMOCRACIA: \\ INTERPRETACIONES ACERCA DE UNA INCOMPATIBILIDAD
}

\author{
Francisco Mata Machado Tavares - Universidade Federal de Goiás - Goiânia - Goiás - Brasil \\ franciscotavares@ufg.br
}

Pedro Vitor Garcia Ramos - Universidade Federal de Goiás - Goiânia - Goiás - Brasil
pedrovgarcia4@gmail.com

\begin{abstract}
Resumo
A política fiscal contracionista mais severa da história recente do capitalismo, quiçá a maior já proposta na história da humanidade, toma forma no cenário brasileiro em dezembro de 2016. A Emenda Constitucional 95 legisla sobre os gastos públicos, impedindo a crescença dos gastos destinados às despesas primárias durante vinte anos e excluindo do debate a restrição do aumento concernente aos juros da dívida pública e à rolagem desta. Além disso, essa emenda não contempla as empresas estatais não dependentes, responsáveis por aumentar o passivo da União sem controle dos principais órgãos de manutenção do orçamento público. Sob um prisma teórico, o quadro acima pode ser lido a partir das lentes de Schumpeter (1991), que antevira o fim do Estado-Tributo ainda em 1918, quadro que parece efetivar-se nos dias atuais, sob as crises fiscais em diversos países do mundo. Estaríamos, possivelmente, sob um cenário que Colin Crouch (2004) definiu como pósdemocracia, também com intuito de mostrar os efeitos negativos que a política fiscal contracionista apresenta em relação aos regimes democráticos atuais. Sob o contexto histórico em que se discute globalmente a relação entre as políticas econômicas aplicadas após a crise de 2008 e as consequências ao Estado democrático, suscita-se a seguinte pergunta: o novo Regime Fiscal Brasileiro, ao reduzir o provimento de direitos humanos fundamentais e a capacidade estatal do governo brasileiro, aumenta uma potencialidade redutora sobre os níveis de democracia fiscal (Habermas, 1998; Tilly, 2007)?

Palavras-chave: Democracia, austeridade, índice de democracia fiscal, regime fiscal.
\end{abstract}

\section{Abstract}

The most severe contractionary fiscal policy in the recent history of capitalism, perhaps the largest ever proposed in the history of mankind, takes shape in the Brazilian scenario in December of 2016. Constitutional Amendment 95 legislates on public expenditures, preventing the increase in spending for primary expenses for twenty years and excludes from the debate the restriction of the increase of the interest of the public debt and its rollover, as well as not contemplating the non-dependent state enterprises, responsible for increasing the Union's liabilities without control of the main organs of maintenance of the public budget. Under a theoretical prism, the above picture can be read from Schumpeter's vision (1991 which had anticipated the end of the Tax State as early as 1918, a framework that seems to be taking place today, under fiscal crises in several countries around the world. We would possibly be under a scenario that Colin Crouch (2004) defined as post-democracy, also in order to show the negative effects that the contractionary fiscal policy presents in relation to the current democratic regimes. Under the historical context in which the relationship between the economic policies implemented after the 2008 crisis and the consequences to the democratic State is discussed globally, the following question arises: Does the new Brazilian Fiscal Regime, by reducing the provision of fundamental 
human rights and the state capacity of the Brazilian government, increases a reduction potentiality on the levels of fiscal democracy (Habermas, 1998; Tilly, 2007)?

Keywords: Democracy, austerity, index of fiscal democracy, fiscal regime.

\section{Resumen}

La política fiscal contractiva más severa de la história reciente del capitalismo, quizá la mayor ya propuesta en la história de la humanidad, toma forma en el escenario brasileño en diciembre de 2016. La enmienda constitucional 95 legisla sobre los gastos públicos, impidiendo el crecimiento de los gastos destinados a las despesas primarias durante vinte años y excluyendo del debate la restricción del aumento referente a los intereses de la deuda pública y al aplazamiento de esta, así como no contemplando las empresas estatales no dependientes, responsables por aumentar el pasivo de la Unión sin control de los principales órganos de manutención del presupuesto público. Bajo un prisma teorético, el cuadro arriba puede ser leído a partir de las lentes de Schumpeter (1991), que antevió el fin del Estado-Tributo en el 1918, cuadro que parece concretarse en los días vigentes, con las crisis fiscales en diversos países del mundo. Estaríamos posiblemente bajo un escenario que Colin Crouch (2004) definió como pos democracia, también con la intención de mostrar los efectos negativos que la política fiscal contractiva presenta a los regímenes democráticos vigentes. Bajo el contexto histórico en que se discute a nivel mundial la relación entre las políticas económicas aplicadas después de la crisis de 2008 y las consecuencias al Estado democrático, se propone la siguiente pregunta: el nuevo Régimen Fiscal Brasileño, al reducir la provisión de derechos humanos fundamentales y la capacidad estatal del gobierno brasileño, iaumenta una potencialidad diminutiva sobre los niveles de democracia fiscal (Habermas, 1998; Tilly, 2007)?

Palabras clave: Democracia, austeridade, índice de democracia fiscal, régimen fiscal.

\section{Introdução}

O objetivo central da pesquisa aqui relatada foi identificar e analisar a correlação entre o Novo Regime Fiscal brasileiro e os níveis de democracia fiscal do país após a implementação da Emenda Constitucional (EC) 95 (Brasil, 2016). No início, procurou-se trazer à pesquisa os argumentos contrários à rigidez fiscal que foram produzidos por Steuerle e Roeper (Steuerle, 2014) por meio do Índice de Democracia Fiscal (IDF), adaptando-os para a realidade brasileira, a qual possui diversos orçamentos segmentados para cada conta nacional. Entretanto, antes de realizar a adaptação, foram identificados alguns limites nas inferências dos autores e na própria concepção do índice, o que gerou uma discordância com os escritores estadunidenses, optando-se, portanto, por adequar-se os rumos da pesquisa aos achados obtidos em seu curso, de modo a formular, antes de uma aplicação, uma crítica ao IDF. No que concerne à abordagem do Novo Regime Fiscal brasileiro, confirmou-se a hipótese que o caracteriza como um elemento potencialmente nocivo ao regime democrático no país.

Optou-se por escolher a modalidade de estudo de caso baseado na epistemologia de Flyvbjerg (2001), pois o argumento proposto por esse autor é o de que os casos escolhidos para análise não podem ser aleatórios. 
Um tipo promissor de caso válido para a pesquisa social, segundo o autor, é o caso extremo. Sendo assim, a EC 95 (Brasil, 2016) foi eleita para a pesquisa por se tratar da mais severa medida de austeridade até aqui aplicada mundialmente, assim caracterizada sob o critério da rigidez (constitucional), da duração estipulada (20 anos) e da abrangência (não há exceções para variações demográficas ou para crescimento econômico).

\section{Estado Moderno como Estado-Tributo}

Nesta seção, busca-se situar a noção de Estado-Tributo, figura central para a contextualização do objeto da pesquisa efetivada. O objetivo de solidificação deste argumento será feito por meio da contextualização histórica produzida por Schumpeter (1991). O autor referido, em seu texto The Crisis of Tax State, descreve a transição do Estado para o Estado Fiscal ${ }^{1}$. Utilizando a figuração de um príncipe austríaco para tratar do ente estatal, o autor aborda a cobrança de tributos sobre os entes privados para o custeio da defesa contra as guerras, à época recorrentes. Essa atividade, até o momento, não era precedia por constante negociação com os demais representantes da sociedade, já que apenas era aceito o pagamento de uma parte da renda produzida pelo indivíduo.

Após o Chefe de Estado enxergar que não era possível pagar as contas, já estando saturados os empréstimos feitos com seus vassalos, ele institui os tributos por meio de negociações que incluíam a esfera privada, justificados por meio da vitória na guerra como um bem de interesse público. Sendo assim, a separação entre o que era público e o que era privado estava consolidada. Schumpeter (1991) afirma ainda que as individualidades dos mercenários participantes do exército, dos vassalos e dos cidadãos comuns da época foram necessárias para que, em seguida, ocorresse a instauração do desejo comum, que, no caso austríaco daquela época, eram as vitórias nas conflagrações. Com o passar do tempo, o Estado começou a cobrar mais tributos sobre diversas atividades na economia e a complexidade do sistema tributário teve um aumento significativo, assim como a variedade dos modos de coleta, mostrando que as exações não só criaram essa forma estatal, mas também moldaram a estrutura social vigente (Schumpeter, 1991).

A incidência de tributos sobre os entes privados é uma atividade com o teor negativo para os indivíduos, tendo em vista que há uma 
supressão de uma parte da renda privada. Isto posto, o indivíduo não se contenta em conceder parte de sua remuneração e não poder legislar sobre o que acontece com o montante recolhido pelo Estado. Assim sendo, o povo começa a exigir participação na decisão pública, fazendo com que os organizadores estatais passassem a aceitar um processo de concessão das decisões aos indivíduos. Esse processo indica que o governo inicia o compartilhamento do poder com o povo, tendo que ceder parte do aparato estatal às demandas populares. Este argumento ficará mais claro na seção seguinte, com Charles Tilly (2007), assim como com um aprofundamento sobre a relação da democracia com a capacidade estatal.

\section{Democracia e capacidade estatal}

O objetivo particular desta seção é apresentar a definição da categoria democrática em relação à visão de Charles Tilly (2007) e relacioná-la com a capacidade estatal. A importância de ter uma explicação clara sobre a democracia é visível quando esta serve de base para a caracterização dos regimes (democrático ou não democrático) espalhados pelo mundo, onde são encontrados diversos casos em que ela se estabelece na constituição, todavia na prática não se mostra como tal; ou onde existe um aparato constitucional que traz o regime democrático, porém o Estado não tem alcance fiscal suficiente para prover os direitos básicos. Dois exemplos seriam o Cazaquistão, que apresenta uma constituição democrática, entretanto o presidente Nazarbayev pratica uma ditadura com forte repressão, e a Jamaica, que se encontra com indícios fortes de democracia ${ }^{2}$, porém ainda não consegue estabelecer uma forte presença estatal para contribuir de forma ativa com os cidadãos jamaicanos (Tilly, 2007). Sendo assim, a elucidação dessa categoria polissêmica será de grande proveito para a continuidade do trabalho, aplicando, mais à frente, uma crítica construtiva ao índice de democracia fiscal e à Emenda Constitucional 95.

Resgatando o ideal poliárquico de Robert Dahl (1990), Charles Tilly (2007) aprimora a definição de democracia do referido autor, pois entende que a relação pode ser dada, simplificadamente, pelo grau das relações políticas entre os cidadãos e o Estado no que tange à amplitude e à igualdade das políticas públicas (pelo lado da cidadania), e à proteção conjuntamente com a consulta aos interesses populares. A democracia, segundo Tilly (2007), é caracterizada pela junção dessas quatro categorias. 
A noção posta pelo autor alia a capacidade estatal ao aumento do grau de democracia de uma nação, dado que alguns pontos estão altamente correlacionados com a eficácia da instituição estatal.

A capacidade estatal pode ser entendida como o alcance de uma intervenção governamental na esfera privada, não sendo somente a magnitude do processo, mas também a fluidez com a qual as políticas públicas conseguem alcançar os objetivos colocados no projeto de governo durante o período pré-eleitoral (Tilly, 2007). Um determinado montante investido em saúde, por exemplo, não seria suficiente para determinar a capacidade estatal por si só. Antes, seria necessário analisarem-se as consequências diretas e indiretas dessa política, pois estas servem de base para a medição da eficiência (alcance); as consequências, por sua vez, seriam mais profundas e permanentes quanto mais organizadas e bem estruturadas fossem as instituições governamentais. A capacidade estatal também pode ser compreendida como a imposição do Estado perante as empresas privadas, medida pela dependência dele em relação a estas, ou seja, uma organização estatal que é vulnerável a sucessivos pedidos de grandes multinacionais, com interesses pessoais dos presidentes das firmas, tem um grau menor de democracia, dado que as decisões governamentais estão em constante mudança e cercadas por decisões privadas $^{3}$, dificultando a validação dos pedidos populares.

Essa dependência do Estado, em constante negociação com as empresas e entes privados, está relacionada à ideia já apresentada na seção anterior com Schumpeter (1991), em que o órgão estatal, minado de capacidade estatal, necessita da interlocução com os agentes para a obtenção de mais recursos. Em troca, o governo deve estabelecer o provimento de um maior controle sobre a máquina estatal, caracterizando o regime como mais democrático. A máxima de Tilly (2007) é que quanto mais o Estado recolhe dos indivíduos em forma de tributo, maior deve ser o nível do país em termos de democratização. A ideia contrária também é válida, ou seja, quanto menos o Estado tributa na esfera privada, menos satisfação sobre as decisões é necessário oferecer ${ }^{4}$. O caso brasileiro, a partir da Emenda Constitucional 95 (Brasil, 2016), pode ser citado como exemplo do segundo argumento.

É importante frisar que a capacidade estatal não é a única responsável pela caracterização de um regime como democrático. A experiência passada no cenário brasileiro corrobora essa afirmativa 
ao mostrar que, em plena ditadura militar, o Estado tinha um imenso poder para modificar as relações na esfera privada e uma influência volumosa para não ser tão afetado por opiniões externas, assim como acontece na ditadura do Cazaquistão comandada por Nazarbayev e apresentada por Tilly (2007). A tese de Tilly (2007), contudo, indica que o aumento da capacidade estatal leva à ulterior democratização, diante da necessidade que o aparato burocrático e seus governantes possuem de obter aquiescência com o respectivo custeio. Não sem um misto de ironia e precisão histórica, o autor chega a asseverar que regimes autocráticos como os de Luís XIV ou Putin abrem, paradoxalmente, o cenário histórico para pressões democratizantes. De qualquer modo, a definição de democracia, anteriormente colocada, apenas se correlaciona com a capacidade estatal, mas não lhe é equivalente. Assim, deve-se levar também em consideração a proteção e consulta constante.

\section{Democracia, direitos humanos e a crítica ao Índice de Democracia Fiscal}

As ações tomadas por um governo impactam nos períodos subsequentes, ainda mais quando se trata de projetos realizados que exigem uma alta carga orçamentária para a sua manutenção. Sendo assim, fez-se um esforço para a elaboração do Índice de Democracia Fiscal. Os autores estadunidenses Eugene Steuerle e Timothy Roeper buscam medir essa flexibilização fiscal sob a premissa teórica de que, quanto mais democrático for um país no campo fiscal, maior será a flexibilização do Estado para escolher as prioridades que receberão investimento e, assim, o voto terá um maior efeito sobre essa decisão (Steuerle, 2010). Esse índice foi adaptado à realidade alemã pelos autores, críticos à austeridade, Wolgang Streeck e Daniel Mertens (2010). A princípio, seria pertinente a sua aplicação ao contexto brasileiro, com vistas ao desenvolvimento do argumento que se pretende discutir neste artigo. Não é o caso, contudo, conforme justificam as razões abaixo.

Antes de adentrar nas teorias que apontam os limites do Índice de Democracia Fiscal, é relevante a explicação do cálculo por trás deste, assim como dilucidar as conclusões do autor estadunidense Eugene Steuerle (2014).

A começar pela definição do índice em si, tem-se que, em palavras, é possível delimitá-lo como sendo um medidor das partes encontradas no 
orçamento da receita federal após a subtração de gastos comprometidos com programas permanentes que não precisam de aprovação de um congresso ${ }^{5}$; todavia, do ponto de vista algébrico, é observável a fórmula do índice como: 1-[(gasto obrigatório+juros) $\div$ receitas]. Sendo assim, quanto maior a receita, maior será o valor assumido pelo IDF, e ainda, um aumento nos juros ou nos gastos obrigatórios fará com que a diminuição do valor final ocorra ${ }^{6}$.

Ao atentar-se à equação em relação a suas contas separadas, é visível que a única parte de difícil cálculo para a maioria dos países é o "gasto obrigatório", dado que os elementos deste variam bastante por conta das constitucionalidades de cada Estado. Quando outros acadêmicos desejam reproduzir o índice para o país natal (ou para qualquer outra nação), será inviabilizada a comparação com o resultado norte-americano. O caso da tentativa alemã é um exemplo, pois os autores tiveram de selecionar algumas contas específicas que eles julgavam extremamente mandatórias/vinculadas para o orçamento público, tendo em vista que o parlamento alemão não se comporta da mesma forma que o estadunidense. Sendo assim, a escolha dos gastos obrigatórios que irão compor o índice nunca alcançará satisfatoriamente os requisitos metodológicos da comparabilidade e da replicabilidade.

O gráfico abaixo é retirado do artigo An index of fiscal democracy, escrito pelo Streeck e Mertens (2010), e mostra a dinâmica do IDF de 1970 até 2010, com uma previsão para 2020. Uma análise simples do gráfico leva à conclusão de que, ao longo do tempo, o índice mostra uma queda acentuada, aproximando-se de zero. Ou seja, admitidas as premissas do índice, a democracia fiscal americana diminui com o tempo, tendo em vista que os gastos discricionários estão se reduzindo cada vez mais com o passar dos governos, corroborando a hipótese levantada por Steuerle (2014). Tem-se também um momento em que o valor passa da marca zero, indicando que, em alguns anos posteriores à crise financeira de 2008, houve um comprometimento total do orçamento da União com os gastos obrigatórios e pagamento de juros da dívida pública. A razão por trás da diminuição do índice é o declive acentuado na receita, fruto da falta de arrecadação produzida pela crise econômica, tendo, neste cenário e em seguida, um desequilíbrio do orçamento, já que a adaptação das despesas governamentais não se ajusta com tremenda rapidez, em vista do aparato constitucional e burocrático da nação. 


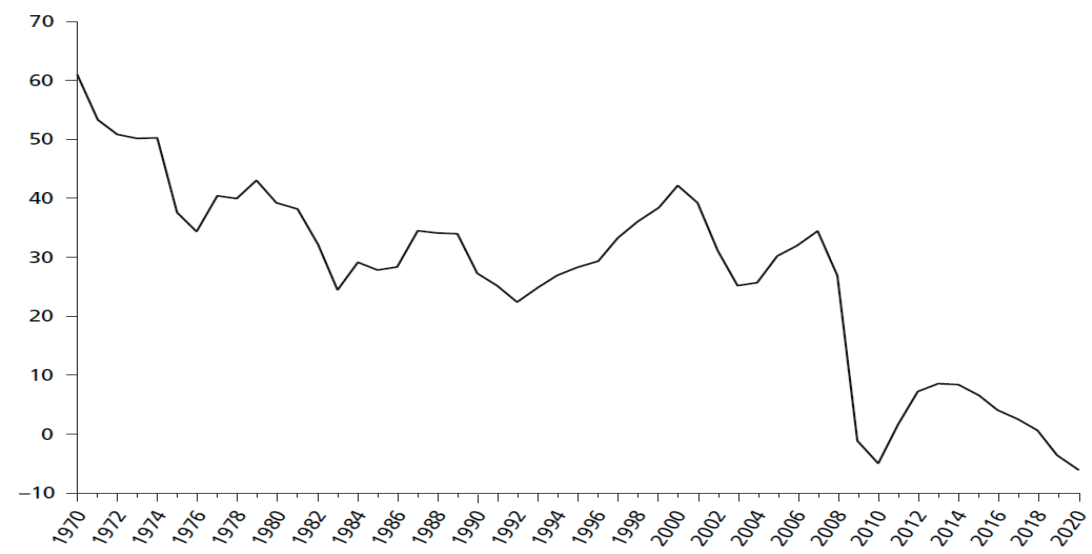

Gráfico 1 - Índice de Democracia Fiscal (Steuerle-Roeper - 1970

-2022). Percentual da receita governamental

Fonte: cálculo de W. Streeck com base em dados da Historical Tables e

Budget and Economic Outlook (Streeck; Mertens, 2010).

A conclusão imediata que o autor americano teve do seu próprio índice muitas vezes é parcial, tendo em vista que o foco em cima do numerador (responsável pelo gasto mandatório e juros) é maior do que no denominador (receita), ou seja, a discussão feita no livro, Dead Men Ruling, em que Steuerle (2014) discute seu índice histórica e teoricamente, assim como nos papers originais ${ }^{8}$ que tratam do IDF, está pautada em cima do corte de gastos obrigatórios da nação e diminuição da dívida. Pouco é falado sobre uma expansão da capacidade de arrecadação estatal, aparato que também diminuiria a rigidez fiscal ${ }^{9}$, isto é, em nenhum momento foi levantada a hipótese das oscilações negativas ou positivas sobre a receita corrente, indicando assim que o valor calculado do índice tem uma tendência ergódica de aproximação negativa.

A concepção inicial da pesquisa que informa este artigo tinha como ambição central a formulação de um índice adaptado à realidade brasileira para a medição da democracia fiscal, pretendendo-se chegar a conclusões e resultados parecidos com os de Steuerle (2014), sugerindo que a rigidez fiscal trazida pela Emenda Constitucional 95 (Brasil, 2016), de fato, traria uma diminuição do nível democrático. Todavia, chegou-se à conclusão de que a proposta não é aplicável, pois o corte de gastos associado a um 
aumento no nível democrático é uma proposta paradoxal, permitindo mudar o foco do trabalho e abrindo margem para apontamentos sobre os limites do índice e das soluções de seu criador.

A começar por um filósofo alemão chamado Jürgen Habermas, a primeira crítica posta ao Índice de Democracia Fiscal é, justamente, a respeito da proposta de corte dos gastos obrigatórios para aumentar o valor do IDF. Em seu livro, The Inclusion of the Other, Habermas (1998) consolida a equiprimordialidade entre os direitos humanos e a democracia, ou seja, em uma perspectiva lógica, e não cronológica, a presença do regime democrático pressupõe a garantia dos direitos humanos. A compreensão por trás dessa máxima está pautada na autonomia privada dentro da sociedade, sendo esta a responsável pela criação das leis, ou seja, sem a garantia dos direitos básicos aos cidadãos que elaboram essas leis, não seria possível chegar a uma autonomia pública e, consequentemente, não haveria uma soberania popular (democracia). Isto posto, é razoável concluir que existe uma equiprimordialidade entre democracia e direitos humanos, assim como entre autonomia privada e pública (Habermas, 1998).

Voltando à crítica do IDF, tem-se que a maioria dos gastos obrigatórios de uma nação, sendo estes escolhidos pelos autores ou garantidos pelo Congresso, irá conter despesas voltadas para a garantia desses direitos. Portanto, é incongruente um corte de gastos associado à garantia da melhora do nível democrático, tendo em vista que a política fiscal contracionista irá reduzir níveis de educação, saúde, entre outros, caso seja aplicada com o intuito de diminuir os gastos mandatórios/ vinculados. Steuerle (2014) enxerga o problema da rigidez fiscal, que, de fato, é preocupante para qualquer nação devido à soberania democrática, porém a solução proposta pelo autor não é factível, já que existem outras formas para diminuir o índice. Buscar uma expansão na capacidade de arrecadação tributária ou sustar as desonerações fiscais cruciais para o orçamento público podem ser ações trazidas como exemplos.

Outro limite apresentado no texto do Steuerle (2014) é a concepção do que seria a democracia. Há dificuldade de encontrar em seus escritos uma definição que dê conta do vasto debate ocorrente ao longo Do século XX entre as distintas correntes da teoria democrática contemporânea. O autor entende que a soberania popular é respaldada somente durante o período eleitoral, pois muito se fala sobre a diminuição da efetividade dos votos. Todavia, os regimes democráticos atuais permitem uma maior 
participação popular por meio de inúmeros arranjos participativos excedentes e complementares ao sufrágio (Santos; Avritzer, 2002; Cohen; Fung, 2004).

A democracia vai muito além desta análise momentânea sobre o poder do voto e, em um horizonte histórico mais amplo, guarda relação com a noção de capacidade estatal, discutida na seção anterior. A ideia de corte de gastos públicos associada à restauração do nível democrático afigura-se contraditória, porque um corte de gastos mandatório pode aumentar a flexibilidade no orçamento, porém compromete a eficiência estatal em contribuir para a melhoria de vida da nação, conceito ligado à capacidade estatal de Tilly (2007). Pode-se, ainda, inferir, utilizando as novas concepções sobre democracia aqui apresentadas, que o fato do orçamento público ser menos rígido não implica, necessariamente, em convertibilidade imediata para graus de democracia, dado que o destino final desse montante financeiro ainda será decidido pelos gestores públicos, podendo se encaminhar para contas destinadas aos direitos humanos ou para lugares de onde a população não usufrui tanto, como o pagamento de juros da dívida pública.

Já salientado anteriormente, existem diversos casos de países com uma imensa capacidade estatal, porém com baixa adesão a programas de incentivo popular, assim como inúmeros regimes com altos indícios de democracia e baixas condições de se impor ao interesse das grandes empresas privadas nacionais. Não é somente a capacidade estatal que irá importar para indicar a democraticidade de um regime, porém é uma variável de exímia importância. Uma diminuição ou congelamento dos gastos públicos sugere uma contração no que se entende por democracia ${ }^{10}$, indicando o caminho contrário proposto pelos autores norte-americanos.

A última seção de críticas ao Índice de Democracia Fiscal tem uma origem algébrica e se encontra na própria fórmula deste. Há um tratamento igualitário das contas "gastos mandatórios" e "pagamento de juros”, mesmo que essas duas contas não se comportem da mesma forma quando se trata do objetivo final. Pagamento de juros/rolagem da dívida pública beneficia um grupo específico de credores que são a favor de gastos mais exacerbados com essa conta macroeconômica. Por outro lado, os gastos obrigatórios, como já discutido anteriormente, podem ter em seu âmago diversos gastos com fins sociais e a população de baixa renda costuma demandar mais esses recursos. Acontece que no IDF essas duas contas estão no numerador, não dando importância para a separação das duas, 
portanto não se calcula o impacto parcial de uma rubrica na variável aleatória final (o valor do próprio índice). Uma possível correção seria calcular um índice dividindo os gastos discricionários pela receita ${ }^{11}$, já que a intenção de Steuerle (2014) é calcular a margem de gasto que o governo tem em relação às receitas correntes e, assim, não haveria problema calculá-lo dessa forma. Pensando num exemplo intuitivo, pode-se ter uma situação em que o gasto com juros aumente, o gasto obrigatório diminua, fazendo com que a receita diminua (multiplicador fiscal); porém o governo decide aumentar a arrecadação tributária e mantém a receita estável no curto prazo, o que fará com que o IDF se mantenha quase constante e não seja percebida a atrocidade cometida com os gastos como saúde, segurodesemprego, aposentadoria etc.

Acontece que o exemplo hipotético citado acima pode ser transportado para o atual cenário brasileiro no contexto da EC 95 (Brasil, 2016), sendo ela o Novo Regime Fiscal. Uma parte do orçamento público é preenchida pelo pagamento dos juros e rolagem da dívida pública, sendo que essa conta nacional não está contemplada no texto institucional da antiga PEC 241, ou seja, a política de corte de gastos não irá incidir nos juros, sendo assim, de forma proporcional, haverá um aumento da participação do pagamento de juros no orçamento da União e, consequentemente, uma diminuição no valor nominal do índice ${ }^{12}$, pois o numerador será aumentado dado o aumento na conta "juros". Ao mesmo tempo, tem-se um corte de gastos públicos primários durante vinte anos, podendo diminuir o numerador do IDF de forma indireta, dado que os gastos primários, mesmo sendo discricionários, são capazes de apresentar um impacto na diminuição da demanda agregada, e, com isso, afetará de forma negativa o gasto mandatório da União e a capacidade de extração dos impostos, devido à diminuição da renda privada, diminuindo a receita governamental. Esses dois movimentos podem se anular dentro do cálculo do índice, pois a austeridade aumenta o valor nominal do IDF e a queda da receita o diminui. Após isso, o governo brasileiro pode optar por aumentar a carga tributária para honrar com os compromissos feitos e com os gastos obrigatórios estabelecidos em lei (movimento realizado pelo governo Temer). Esse efeito causa no índice um aumento do valor nominal, entretanto, no agregado, a cotação final pode se mostrar constante, deixando despercebida a manobra fiscal feita, já que esse impacto pode ter seu montante igualado à diminuição inicial no índice provocada pela crescença do pagamento de juros (primeira etapa do 
exercício de estática comparativa). Isso implica que o índice não consegue captar de forma precisa o andamento da economia brasileira, e não só desta economia, fazendo com que seja subestimado o valor final - distorcido para diversas situações, pois, corroborado, pelo exemplo acima, o índice abre a possibilidade de permanecer com valores constantes, mesmo que haja uma grande mudança constitucional e estrutural no país, sendo esta, no caso brasileiro, a EC 95.

O índice composto dessa forma pode servir de pretexto para a argumentação a favor de políticas neoliberais como austeridade ou até mesmo para os argumentos a favor do corte de gastos obrigatórios estritamente sociais, ficando a cargo do pesquisador a melhor forma de utilizá-lo.

Descartada a abordagem sobre a relação entre democracia e austeridade no Brasil atual com esteio no IDF, as seções seguintes pretendem conferir um tratamento alternativo, de fôlego interpretativo, à matéria.

As políticas econômicas dos governos PT's (2003-2014)

Após algumas décadas de governos preocupados com estabilização dos agregados macroeconômicos, tem-se uma transição governamental bastante estudada dentro da área político-econômica brasileira. Cercada de grande insegurança por parte dos credores da dívida, assim como por parte dos investidores (estrangeiros e nacionais), o primeiro período eleitoral do novo milênio traria um novo partido à presidência da república na figura de Luiz Inácio Lula da Silva. A geração de desconforto era então atribuída ao antigo discurso ${ }^{13}$ aliado aos ideais mais radicais do Partido dos Trabalhadores (PT).

Por mais que fossem constatados pontos de divergência para com os governos anteriores, é possível caracterizar o primeiro governo Lula como mantendo traços significativos de uma política neoliberal, assim entendida como aquela segundo a qual o parâmetro para avaliação e legitimação da atuação estatal reside no âmbito da economia de mercado que, desse modo, não apenas é liberada de significativa ingerência estatal (como no liberalismo clássico), mas avança para intervir, regular e definir a atuação do Estado (Brown, 2015). 
A justificativa para essa classificação é dada através do não rompimento com algumas políticas adotadas (tanto fiscais quanto monetárias) nos mandatos passados. Lula deveria manter a palavra da não-mudança para o mercado ${ }^{14}$ e para isso nomeou Henrique Meirelles um economista ortodoxo que chegara à presidência do Banco de Boston - para presidente do Banco Central e Antonio Palocci para ministro da Fazenda, contrariando a expectativa da mídia e do povo, que esperavam Guido Mantega, economista heterodoxo com históricas ligações com o PT, como Ministro da Fazenda. Esse indicativo aponta o que seria feito com as políticas fiscais e monetárias durantes os três próximos anos de governo: elas ficariam sob supervisão do FMI.

Como era de se esperar, com Meirelles na presidência do BACEN, o receituário para combate à inflação era a diminuição da oferta monetária, dado que estava sendo seguido um diagnóstico monetarista (Milton Friedman), ou seja, a inflação era encarada como um fenômeno puramente monetário. No Brasil, portanto, foram adotadas as gigantescas taxas de juros ${ }^{15}$ e, mesmo após um resultado imediato nos primeiros anos de governo (devido a políticas adotadas no governo FHC e ao boom das commodities), não sobreveio a remuneração que se espera em situações de renúncia à liquidez, sendo dada a justificativa que era necessária uma alta manutenção dessa taxa para que o capital estrangeiro não saísse do país e, com isso, fosse permitida uma rolagem da dívida pública. Os superávits conseguidos nos primeiros anos de governo tiveram um importante papel para a valorização do real no período, fazendo com que houvesse uma desvalorização do dólar em 32\% (valores reais). Esse argumento foi usado para justificar o controle ocorrido da inflação por economistas heterodoxos (em contraposição à ideia da âncora monetária), visto que os produtos importados estavam baratos e a demanda interna se deslocou para um mercado distante. Todavia, a criação desse superávit também pressupôs um aperto fiscal para inalteração do gasto, e as consequências de uma política fiscal restritiva são dadas em inúmeros trabalhos científicos, passando da queda do nível do produto para o encolhimento da economia (Souza, 2008).

Marcada por escândalos como a quebra do sigilo bancário de Francenildo Costa, caseiro do Ministro Antônio Palocci, e por esquemas de corrupção na figura do "mensalão", essa transição indicou que o governo precisaria de um impulso para fazer o país voltar a crescer (tendo sofrido uma desaceleração em 2005). Tendo como fim este objetivo, foi retirado 
o então ministro da fazenda Antonio Palocci substituindo-o por Guido Mantega (assessor econômico de Lula desde a campanha de 1989). Os perfis dos dois economistas em análise são bem divergentes quanto à política fiscal, sendo que o daquele tem um caráter bem mais restritivo, como foi mostrado em partes do texto, e o deste se encaixa mais nos planos desenvolvimentistas do governo da época. Outro motivo claro que está por trás dessa decisão política é a necessidade de ganhar as eleições de 2006, aumentando, portanto, o gasto público voltado para o crescimento econômico e gerando um aumento da renda privada e, consequentemente, um aumento do produto. Em 2006, Luiz Inácio Lula da Silva consegue desbancar Geraldo Alckmin e é reeleito presidente da república com 61\% dos votos válidos.

Logo após a tomada da posse da república, a primeira medida, no que tange à política fiscal do governo, foi a instauração do Programa de Aceleração do Crescimento (PAC), sendo que o crescimento da economia era o principal objetivo a ser alcançado no segundo mandato do PT. Depois de todo debate na esfera pública sobre o monetarismo e as ideias desenvolvimentistas, esse programa trouxe à tona a vitória dos ideais de Mantega e de Dilma Rousseff (Casa Civil) e, além disso, mostrou uma direção que o segundo governo ia tomar, sendo ela totalmente contrária à visão restritiva do primeiro mandato.

O PAC tinha como objetivo principal atingir três metas, sendo a primeira a aceleração do crescimento econômico (meta de 4,5\% do PIB em 2007 e 5\% ao ano até 2010); depois, o aumento do nível de emprego; e a melhoria das condições de vida da população brasileira. Para que os objetivos primários fossem atingidos, o plano contava com cinco grandes blocos que deveriam ser focados com o passar dos anos: investimento em infraestrutura; estímulo ao crédito e ao financiamento; melhora do ambiente de investimento; desoneração e aperfeiçoamento do sistema tributário e medidas fiscais de longo prazo (cf. Souza, 2008).

Por mais que houvesse uma forte frente para a condução do programa, é necessário lembrar que Meirelles ainda presidiava a cadeira do BACEN, fazendo com que a queda na taxa de juros fosse bem menor do que um plano desenvolvimentista prevê ${ }^{16}$, visto que era necessário um aumento na eficiência marginal do capital, realizado por uma queda no valor dos bens de capitais. Outras limitações que o programa enfrentou fazem jus ao caráter burocrático do Estado, trazendo à tona problemas para obtenção de licenças ambientais, problemas com o Tribunal de Contas da 
União (TCU), judicialização de licitações e casos de corrupção envolvendo órgãos que estavam ligados diretamente com as diretrizes do programa (cf. Werneck, 2014). A maioria desses entraves foi justificada pela governança como sendo a falta de um período contínuo da gestão estatal tomando conta do investimento, já que não se fazia algo desta magnitude há mais de vinte anos ${ }^{17}$. Ainda com diversos problemas, o PAC conseguiu dar resultados significativos no que tange ao objetivo central do programa, fazendo com que a taxa de crescimento do PIB aumentasse de $3,2 \%$ em 2005 para mais de $5 \%$ em 2007, criando assim mais de 1,5 milhões de empregos formais (Souza, 2008).

Iniciado em meio a uma crise mundial ${ }^{18}$, o primeiro governo Dilma teve como foco principal a retomada de um crescimento que não demonstrava os mesmos níveis que foram apresentados durante a década passada. Porém, a condução da política fiscal, assim como a definição da taxa de juros não foram tão bem aproveitadas para que se houvesse uma recuperação na linha de crescimento vista anteriormente, mesmo que, em tese, os anos Dilma se apresentariam mais expansivos, dado que as metas para superávit primário tinham sido estabelecidas abaixo do nível anterior.

Quando se analisa o consumo do governo central, tem-se um aumento se comparado com os níveis anteriores, porém o caráter recessivo da expansão dos gastos é mostrado quando são incorporados os gastos no âmbito municipal e estadual, resultando em, de forma agregada, um atrofiamento do consumo público. Em relação ao investimento, houve uma queda vertiginosa no governo Dilma, muito por conta da alta expansão da formação bruta de capital fixo durante o governo Lula, justificada pela atuação pública no PAC (aproximadamente 76\% dos recursos foram públicos). Os índices durante os anos de 2011-2014 foram oscilando entre um ano bom e outro ruim, com exceção, obviamente, para o ano de 2014, quando foram feitos diversos investimentos por conta da Copa do Mundo, das Olimpíadas (que seriam sediadas pelo Rio de Janeiro em 2016), e por conta das eleições presidenciais. Outro fator responsável pela queda do investimento é referente aos esquemas de corrupção na Petrobrás, sendo esta a maior empresa estatal; com isso, parou-se de realizar, no mesmo montante de antes, uma inversão direta de capitais na empresa, comprometendo o nível de investimento dessa forma (Gentil; Hermann, 2017). 
Em relação às despesas sociais, é de se esperar uma alta na taxa de utilização do orçamento público para as políticas sociais durante os 12 anos de PT no poder, por praticarem a distribuição de renda através de diversos programas (Fome Zero, Bolsa Família etc.). Por fim, em relação às políticas tributárias teve um aumento dos tributos para todos os anos de governo, mesmo com altas renúncias fiscais ${ }^{19}$. Os incentivos fiscais também foram uma marca do governo Dilma, com uma gigantesca campanha de redução do Imposto sobre Produtos Industrializados (IPI) para gerar novos investimentos e aumentar o consumo da população sobre máquinas, equipamentos e automóveis. As políticas para distribuição direta de renda também apresentavam dificuldades de obter êxito devido ao grau de endividamento das famílias, assim como devido à alta na taxa de juros, que foi percebida após os anos de 2012 - antes disso, era possível enxergar um grande esforço governamental para manutenção da menor taxa de juros real registrada no sistema SELIC, sendo esta uma das medidas anticíclicas adotadas pela presidenta para ter a volta do crescimento (Gentil; Hermann, 2017).

As falhas cometidas pela escolha de exonerações altas e incentivos através da renúncia de arrecadações públicas (gasto) vão ao encontro da linha de pensamento teórico por trás do erro cometido com a queda da taxa de juros em 2011. Incentivos dados por países podem alavancar a economia e fazer com que haja um aumento na renda, assim como um crescimento produto e um desenvolvimento da nação; todavia, essas medidas devem ser aplicadas em momentos favoráveis, dado que os agentes privados serão seguidos pela boa atmosfera da economia para que a expectativa de lucros futuros seja maior, ou seja, não adiantaria passar concessões para privatização na saúde, ou aumentar a renda privada via não cobrança de impostos ou até mesmo incentivar o consumo através de diversas medidas, se a conjuntura da época não fosse favorável, pois sendo assim o agente privado não iria realizar o investimento, sobrando para a iniciativa pública a responsabilidade de aumentá-lo.

Após um apanhado de políticas fiscais e monetárias adotadas no governo PT, ficou claro que, em suma, essas políticas tiveram um caráter ortodoxo, com foco no primeiro governo Lula (ano da transição) e nos anos conturbados do governo Dilma. A continuação das políticas do tripé econômico, assim como a nomeação de Meirelles e Palocci para cargos executivos importantes trazem a confirmação de traços neoliberais na era Lula, mesmo que tenha havido crescimento, ajudado pelo boom das 
commodities que afetaram todos os países da América Latina. A falta de ousadia do governo Dilma aliada a uma dificuldade de aprovar propostas de cunho mais heterodoxo também foram incapacitantes para solucionar a queda no crescimento do PIB, estendendo-se esse quadro até 2016, quando Dilma Rousseff sofre o impeachment, mesmo tentando passar reformas não condizentes com a linha de pensamento do partido.

\section{A crise de 2015 e a pós-democracia}

Mesmo apresentando características neoliberais durante os anos de 2003-2016, constantemente ligadas aos partidos mais conservadores, a presidenta Dilma sofre um golpe arquitetado por setores sociais (empresariado representado pela FIESP, grandes bancos, estamentos militares, magistrados, grandes veículos de comunicação, dentre outros), cujo anseio por submissão do Estado aos imperativos de redução do custo do trabalho e de redução da política e do direito à lógica da rentabilidade de mercado revelou-se, mormente sob um quadro de decréscimo no preço internacional das commodities minerais e agrícolas, assaz mais intenso do que o governo de Dilma admitira, chegando ao limite de um fanatismo libertariano.

Essa transição do governo para o PMDB parece contraditória, dado que o impeachment realizado tinha como objetivo aprofundar o país numa onda de políticas neoliberais, todavia essa antinomia pode ser entendida como fruto de uma tendência global explicitada por Colin Crouch (2004), entendendo-se que o Brasil está no estado de pós-democracia devido ao caráter neoliberal apresentado pelas políticas públicas realizadas. Crouch (2004) entende que mesmo aumentando o número de democracias formais ${ }^{20}$, estas podem não se mostrarem como um regime democrático, sendo dado aqui o exemplo do caso cazaquistanês, apresentado anteriormente. Crouch (2004) usa uma analogia, ao se referir ao cenário acima, em que é feita uma comparação da história democrática moderna com a equação do segundo grau com o coeficiente "a" negativo (parábola com a concavidade para baixo), compreendendo o valor máximo da função como sendo o período democrático, e, a partir o ponto de inflexão, uma volta aos padrões não democráticos, concluindo que, tendendo a função a infinito, é possível ter uma volta de valores negativos ao avanço feito nos séculos anteriores. 
De suma importância, as origens do golpe não passam despercebidas. A começar por um problema político, Tavares (2018) explicita que a partir do segundo governo Dilma é realizada uma política de austeridade intensa que subtrai os direitos previdenciários de desempregados, viúvas e pescadores artesanais através de medidas provisórias, deteriorando também a capacidade de investimento nas áreas de educação e infraestrutura. Outras instituições paralelas ao Governo Central, como o BACEN, Ministério Público e Judiciário começaram a ganhar voz, dificultando o protagonismo do partido e dificultando a execução dos planos feitos no período pré-eleitoral. A ajuda do povo à realização dessas políticas também se mostrava inviável, tendo em vista que a presença do PT nas frentes de esquerda estava se desgastando. Por fim, Tavares afirma:

A política fiscal neoliberal, o descolamento do Banco Central e das agências reguladoras quanto ao controle social, a autonomia crescente das instituições de controle e a repressão crescente contra a esquerda não partidária insurgente foram traços da política pós-democrática manifestados no governo do PT que, sob o aprofundamento da crise econômica em 2015, ricochetearam como fatores com influência sobre o golpe que despojou o partido da presidência (Tavares, 2018).

Promulgada alguns meses após o golpe no governo Michel Temer, a Emenda Constitucional 95 (Brasil, 2016) toma conta do orçamento público e instaura o Novo Regime Fiscal. O caráter extremo dessa medida é corroborado pela sua duração, sendo vinte anos um período extremamente longo para uma política de austeridade contínua, um prazo rechaçado por órgãos internacionais como o FMI. Além dessa longevidade vintenária, a medida não dispõe sobre o juros e rolagem da dívida pública brasileira, ou seja, seu texto se restringe às despesas primárias, impactando fortemente nos níveis de desenvolvimento do país, assim como na distribuição de renda. Sendo insuficiente, a norma não legisla sobre possíveis crescimentos extraordinários da economia durante o período referido, assim como não leva em consideração processos migratórios ou surtos de natalidade, ou seja, o PIB tendo um crescimento de $20 \%$ ou a população atingindo 500 milhões de habitantes, ainda assim, haverá uma restrição ao gasto público, com as contas afetadas.

A preocupação sobre essa medida não se dá somente no campo das consequências econômicas e sociais. $\mathrm{O}$ aparato político fica totalmente desfigurado e a democracia no Brasil dá continuidade ao processo 
elucidado por Crouch (2004). Os governos seguintes ficarão responsáveis pela tributação da folha salarial e cumprimento constante do orçamento, ausentando do debate eleitoral as autonomias partidárias, que são colocadas em prática através do gasto discricionário, isentado, por sua vez, pela medida do governo Temer (Tavares, 2018).

\section{Conclusão}

A pesquisa apresentada neste artigo procurou associar o regime de austeridade fiscal instituído pela Emenda Constitucional 95 (Brasil, 2016) no Brasil aos destinos da democracia no país. Sob um conceito de regimes democráticos que mobiliza a ideia de capacidade estatal (Tilly, 2007), concebe-se uma mútua pressuposição entre direitos humanos e democracia (Habermas, 1998) e abarca-se mais do que um estrito método de escolha de líderes, para compreender arranjos de participação social (Santos; Avritzer, 2002). Assim, entendeu-se que o índice usualmente adotado para lidar com a relação entre rigidez fiscal e democracia, proposto por Steuerle (2016), encerra inultrapassáveis limites teóricos, além de insuficiências macroeconômicas em sua apresentação algébrica.

Assim, procedeu-se a uma crítica de fôlego teórico e interpretativo do regime fiscal inaugurado pela EC 95 (Brasil, 2016) no Brasil. Apesar de ser pouco provável que o teto de gastos ali dispostos resista ao vintênio para o qual está programado - haja vista o impacto social que ensejará - nota-se que a aprovação da medida e sua simples entrada em vigor comprometem o custeio dos direitos humanos e reduzem a margem de influência dos cidadãos sobre as decisões dos governos, de modo que a medida se enquadra na definição formulada por Colin Crouch (2004) para pós-democracia: preserva-se uma institucionalidade formalmente democrática, mas, à míngua de direitos e de meios para o exercício da soberania popular, o regime perece em favor do primado de formas mercantis, em particular das grandes corporações.

\section{Notas}

10 termo Tax State é utilizado por Schumpeter (1991) para referir-se ao Estado Moderno.

2 Utiliza-se como parâmetro o índice feito pela Freedom House com estimações próprias e apresentado por Tilly (2007). 
3 Essa vantagem do mercado em relação à demanda da população pode ser entendida como uma tensão entre a austeridade e a democracia, sendo esta já bem elucidada por Wolfgang Streeck e Armin Schäfer em 2013 no capítulo inicial do livro Politics in the age of austerity.

4 Uma leitura distinta, a propor que a relação entre tributação e democratização é mediada, adicionalmente, por um exame dos benefícios percebidos em relação aos tributos pagos, pode ser encontrada em Ross (2004).

5 A falta da necessidade de aprovação por um congresso é uma particularidade da política norte-americana.

6 Importante ressaltar que mesmo sendo uma fração, o comportamento do valor numérico da variável será diferente do usual, por conta da diminuição na parte inicial da fórmula do IDF (subtração com o número 1), ou seja, ao aumentar o denominador da fração, haverá uma amplificação do valor final, ao invés de uma queda.

7 As "receitas" e os "pagamentos de juros" são contas que não exigem uma grande dificuldade para serem calculadas, dada à padronização do que se entende pela receita da União, assim como pelo pagamento de juros da dívida pública.

8 Restoring Fiscal Democracy, de 2016, autoria de Eugene Steuerle.

90 termo "rigidez fiscal" é mais adequado para a discussão sobre o índice. O IDF não é um elemento para discussão sobre a democracia, e sim sobre flexibilidade orçamentária, já apresentando o início de uma das críticas ao índice.

10 Salientando tratar dos conceitos apreendidos no projeto até então, sem nenhuma aspiração de generalizar o estado da arte sobre teorias democráticas contemporâneas.

11 Os dois índices seriam complementares, no sentido algébrico, tendo em vista que: gasto total (gastos obrigatórios I juros) gastos discricionários.

12 É necessário considerar cetteris paribus para o exercício de estática comparativa até aqui, no entanto as próximas etapas do contexto deverão ser analisadas em relação ao que já aconteceu no exemplo real da EC 95 (Brasil, 2016).

13 Durante o período de discussão eleitoral, o candidato à presidência pelo PT deixou claro que não haveria tantas mudanças (mudando o discurso feito em eleições antigas) e que a maioria das políticas implementadas no governo FHC seriam continuadas na próxima gestão, transmitindo essa ideia via "Carta ao Povo Brasileiro" ou até mesmo dos debates transmitidos à população.

14 É recorrente nas democracias atuais o governante se preocupar com o mercado e orbitar em um trade-off: população x capital (Schaefer; Streeck, 2013).

15 Foram constatadas à época as maiores taxas de juros do padrão (SELIC) devido a esse errôneo entendimento sobre o aumento do nível de preços.

16 Por conta de diversos superávits conquistados em anos anteriores e de uma volumosa reserva cambial que o país tinha, o Brasil não sofreu diretamente com a crise de 2008, mesmo assim, a economia ainda não tinha um papel soberano no mundo e se a crise atingisse a economia real dos EUA de forma mais severa, o Brasil estaria correndo riscos de se ter uma grande crise. Esse foi um dos motivos que fez com que o BACEN suspendesse a queda dos juros (Souza, 2008). 
17 Com o plano de gestão estabelecido, o Brasil acaba com um período de mais de vinte anos (1981-2006), em que não houve uma diretriz central dos governos, dado que as preocupações de cada época eram a de estabilizar a inflação e os agregados macroeconômicos com planos que nunca duravam mais do que dois anos, com exceção do plano real.

18 Houve uma redução do PIB mundial de 2010 a 2013, assim como uma queda na taxa de crescimento dos países na Zona do Euro de 5,2\% para 2,9\%.

19 Em 2004, o montante da renúncia do governo central era equivalente a 24,2 bilhões de reais, já no período 2011/2014, a abdicação dos impostos começa em 181,3 bilhões passando, no final do governo, para cerca de 250 bilhões (cf. Gentil; Hermann, 2017).

20147 em 1988, 164 em 1995 e 191 em 1999.

\section{Referências}

BRASIL. Emenda Constitucional número 95, de 15 de dezembro de 2015. Altera o Ato das Disposições Constitucionais Transitórias, para instituir o Novo Regime Fiscal, e dá outras providências. Diário Oficial da União, Brasília, DF, 15 dez. 2016. Disponível em: <http:/www.planalto.gov.br/ccivil_03/constituicao/ emendas/emc/emc95.htm>. Acesso em: 25 nov. 2018.

BROWN, Wendy. Undoing the Demos: neoliberalism's stealth revolution. New York: Zone Books, 2015.

COHEN, Joshua; FUNG, Archon. Radical Democracy. Swiss Political Science Review, v. 10, n. 4, p. 23-34, 2004.

CROUCH, Colin. Post Democracy: Cambridge: Polity, 2004.

DAHL, Robert. Um prefácio à Teoria Democrática. Tradução de Ruy Jungmann. Rio de Janeiro: Jorge Zahar, 1990.

FLYVBERG, B. Making Social Science Matter: why social inquiry failed and how it can suceed again. Cambridge: Cambridge University Press, 2001.

GENTIL, Denise; HERMANN, Jeniffer. A Política Fiscal do Primeiro Governo Dilma Rousseff: ortodoxia e retrocesso. Economia e Sociedade, Campinas, v. 26. n. 36, p. 793-816, dez. 2017. Disponível em: <http://www.scielo.br/pdf/ecos/ v26n3/1982-3533-ecos-26-03-793.pdf>. Acesso em: 28 nov. 2018.

HABERMAS, Jürgen. The Inclusion of the Other. Editado por Ciaran Cronin e Pablo De Greiff. Cambridge: The MIT Press, 1998.

ROSS, M. Does taxation lead to representation? British Journal of Political Science, Cambridge, v. 34, n. 2, abr. 2004. Disponivel em: <https://www.sscnet. ucla.edu/polisci/faculty/ross/papers/articles/taxrep.pdf $>$. Acesso em: 25 nov. 2018.

SANTOS, Boaventura de Sousa; AVRITZER, Leonardo. Introdução: Para Ampliar o Cânone Democrático. In: SANTOS, Boaventura de Sousa (Org.). Democratizar a Democracia: Os Caminhos da Democracia Participativa. Rio de Janeiro: Civilização Brasileira, 2002. p. 39-82. 
SCHUMPETER, Joseph A. The Crisis of The Tax State. In: SWEDBERG, Richard (Org.). Joseph A. Schumpeter: The economics and sociology of capitalism. Princeton: Princeton University Press, 1991.

SCHÄFER, A; STREECK, W. Introduction. In: SCHÄFER, A.; STREECK, W. (Ed.). Politics in the Age of Austerity. Cambridge: Polity, 2013.

SOUZA, Nilson. Economia Brasileira Contemporânea: de Getúlio a Lula. São Paulo: Atlas, 2008.

STEUERLE, Eugene. Dead Men Ruling. New York: The Century Foundation Press, 2014. . Restoring Fiscal Democracy. Washington: Urban Institute, 2016. . The U.S. Is Broke: Here's Why. USA Today. Virginia. 27 de janeiro, 2010.

STREECK, Wolfgang; MERTENS, Daniel. An index of fiscal democracy. MaxPlanck Institutz für Gesellschaftsforschung. MPIfG Working Paper, Köln, v. 10, n. 3, abr. 2010.

TAVARES, Francisco. Participação Política no Brasil Pós-Democrático: uma abordagem sócio-fiscal do ocaso da Nova República. ENCONTRO DA ASSOCIAÇÂO BRASILEIRA DE CIÊNCIA POLÍTICA, 11, Anais... Curitiba, 2018.

TILLY, Charles. Democracy. Cambridge: Cambridge University Press, 2007.

WERNECK, Rogério. Alternância Política, Redistribuição e Crescimento. In: ABREU, Marcelo (Org.). A Ordem do Progresso. Rio de Janeiro: Elsevier, 2014.

Francisco Mata Machado Tavares - Bacharel em Direito, mestre e doutor em Ciência Política pela Universidade Federal de Minas Gerais. Professor Adjunto da Faculdade de Ciências Sociais da Universidade Federal de Goiás. Orcid: http://orcid.org/0000-0002-3905-8141

Pedro Vitor Garcia Ramos - Bacharel em Ciências Econômicas pela Universidade Federal de Goiás. Foi Bolsista de Iniciação Científica do GESF-UFG entre 2016 e 2018. Orcid: http://orcid.org/0000-0001-7852-8399

\section{Contribuição dos Autores}

Os autores trabalharam juntos em todas as etapas da pesquisa que respaldou o presente artigo. A investigação científica deu-se no âmbito do Grupo de Estudos de Sociologia Fiscal - GESF, vinculado à Faculdade de Ciências Sociais da Universidade Federal de Goiás. Francisco Tavares coordena o grupo e Pedro Garcia atuou entre 2016 e 2018 como bolsista remunerado de iniciação científica. O levantamento teórico atinente à relação entre democracia e fiscalidade, bem como à ideia schumpeteriana 
de Estado-tributo ficou a cargo de Francisco Tavares, assim como a delimitação do tema, do problema e do percurso metodológico da pesquisa. A discussão sobre o Índice de Democracia Fiscal e seus limites foi tecida em conjunto pelos autores, a partir de discussões ocorrentes no GESF. A abordagem da política econômica dos governos brasileiros foi efetivada por Pedro Garcia, assim como a pesquisa que associa a noção habermasiana de equiprimordialidade entre direitos humanos e democracia à ideia de rigidez fiscal. A primeira redação do texto foi escrita por Pedro Garcia, sob supervisão e com base na definição das seções, temas e respectivos referenciais teóricos estabelecida por Francisco Tavares, que, a partir da primeira versão, atribuiu os contornos finais ao texto.

Recebido para publicação em 22 de junho de 2018 Aceito para publicação em 11 de agosto de 2018 